\title{
Cutaneous Manifestations of Rheumatoid Arthritis
}

\author{
T. Aarthipriya ${ }^{1}$, R. Ravichandran ${ }^{2}$, S. Ramesh ${ }^{3}$, V. Anand ${ }^{4}$, L. Selvaraj ${ }^{5}$, C. Devi ${ }^{6}$ \\ ${ }^{1}$ Department of Rheumatology, Kilpauk Medical College and Hospital, Chennai, Tamilnadu, India. ${ }^{2}$ Department of \\ Rheumatology, Kilpauk Medical College and Hospital, Chennai, Tamilnadu, India. ${ }^{3}$ Department of Dermatology, Kilpauk \\ Medical College and Hospital, Chennai, Tamilnadu, India. ${ }^{4}$ Department of Rheumatology, Kilpauk Medical College and \\ Hospital, Chennai, Tamilnadu, India. ${ }^{5}$ Department of Rheumatology, Kilpauk Medical College and Hospital, Chennai, \\ Tamilnadu, India. ${ }^{6}$ Department of Immunology, Kilpauk Medical College and Hospital, Chennai, Tamilnadu, India.
}

\section{ABSTRACT}

\section{BACKGROUND}

Many cutaneous manifestations have been described in patients with Rheumatoid Arthritis (RA). Percentage of cutaneous manifestations varies from country to country. Only few studies and limited literature are available as on date. Skin manifestations in RA can be related to the disease or due to medications used to treat RA.

\section{METHODS}

From June 2014, 100 consecutive patients fulfilling the revised 1987 American College of Rheumatology (ACR) classification criteria for RA were taken up for this study. Late onset RA \& Juvenile Idiopathic Arthritis were excluded. All patients were routinely evaluated for the skin manifestations with the dermatologist. Immunological tests RF \& Anti CCPAb were done.

\section{RESULTS}

In our study, 97 were females \& 3 were males. $7 \%$ were in $21-30$ years, $24 \%$ in 31 40 years, $40 \%$ in $41-50$ years age group and $29 \%$ in $51-60$ years age group. $38 \%$ had disease duration below 2 years, $42 \%$ of patients had 2-5 years disease duration \& $20 \%$ had more than 5 years duration. RF positivity was noted in $73 \%$ of the patients. 32 patients were tested for Anti-CCPAb, of whom $20(62.5 \%)$ were positive. $26 \%$ of patients had comorbidities (type-2 DM, SHT, Hypothyroidism, CAD, Dyslipidemia). In our study, $15 \%$ of patients had cutaneous manifestations like rheumatoid nodules (4\%), herpes (1\%) and chloroquine induced skin manifestations (10\%) in the form of hypo \& hyperpigmentation, rashes, dry skin and allergic reactions. 7 patients $(46.7 \%)$ with skin manifestations were in the 41 50 years age group. $14(93 \%)$ of them were females and $1(6.6 \%)$ male. $5(44 \%)$ of them had disease duration of $<2$ years whereas $10(66 \%)$ patients had $>2$ years. 12 out of 15 patients with skin manifestations (80\%) had RF positivity. Anti-CCP positivity was $60 \%$ in these patients.

\section{CONCLUSIONS}

Cutaneous manifestations due to drugs are more common than disease per se. Thus, understanding the aetiology and management for cutaneous manifestations of RA will optimize patient care.

\section{KEY WORDS}

Cutaneous, Rheumatoid Arthritis
Corresponding Author:

Dr. Aarthi Priya,

AL 159, $2^{\text {nd }}$ Street, $12^{\text {th }}$ Main Road,

Annanagar, Chennai-40,

Tamilnadu, India.

E-mail: drtapriya@gmail.com

DOI: $10.14260 / j e m d s / 2019 / 724$

Financial or Other Competing Interests: None.

How to Cite This Article: Aarthipriya T, Ravichandran R, Ramesh $S$, et al. Cutaneous manifestations of rheumatoid arthritis. J. Evolution Med. Dent. Sci. 2019;8(44):3337-3341, DOI: 10.14260/jemds/2019/724

Submission 10-04-2019, Peer Review 20-10-2019, Acceptance 26-10-2019, Published 04-11-2019. 


\section{BACKGROUND}

Rheumatoid arthritis (RA) is an immune-mediated, chronic inflammatory disease predominantly affecting joints.[1] However, extraarticular manifestations of RA, including skin disease, are relatively common and occur in nearly $40 \%$ of patients with RA over a lifetime of the disease course.[2] A large number of specific and nonspecific mucocutaneous manifestations are associated with RA.[3],[4] As with other extra-articular manifestations, dermatologic involvement tends to occur in patients with more severe RA. ${ }^{[5]}$ Understanding the cutaneous manifestations of RA may lead to early diagnosis, prompt treatment, and hence lower morbidity and mortality of the affected persons.[3] The database search revealed that apart from a few studies on Western population,[4],[6] there is few data on this subject, particularly on Indian population which prompted us to undertake the present study. The objective of the present study was to find out the different patterns of cutaneous manifestations in RA patients attending the Rheumatology OPD at Kilpauk Medical College, Chennai.

We wanted to study the cutaneous manifestations of Rheumatoid Arthritis patients attending the Rheumatology OPD at Kilpauk Medical College, Chennai.

\section{METHODS}

This cross-sectional study was carried out at the Department of Rheumatology at Kilpauk Medical College, Chennai. over a period of 6 months (From June 2014 to December 2014). The study was approved by the Institutional Ethics Committee. Consecutive 100 RA patients fulfilling the revised 1987 American College of Rheumatology (ACR) classification criteria for RA were taken up for this study. ${ }^{7}$ Exclusion criteria were other autoimmune disorders, rheumatic diseases other than RA and juvenile idiopathic arthritis. Skin findings of each patient were evaluated by rheumatologists and dermatologists. Detailed history and clinical findings of these patients were recorded in a pretested, predesigned, and semi-structured schedule. Rheumatoid factor (RF) tests were done in all patients. 32 patients were tested for anticyclic citrullinated peptides antibody (Anti-CCPAb) tests. Other appropriate laboratory investigations including radiological examination were done as needed.

We studied 100 Rheumatoid Arthritis patients. The age range was 21-60 years with 7\% patients were in 21-30 years, $24 \%$ in $31-40$ years, $40 \%$ in $41-50$ years age group and $29 \%$ in 51-60 years age group with a mean of $41.1 \pm 13.8$ standard deviation (SD). The majority of the patients were female ( $\mathrm{n}=$ 97) while male $(n=3)$ were less. $38 \%$ had disease duration below 2 years, $42 \%$ of patients had 2-5 years disease duration \& $20 \%$ had more than 5 years duration. The mean disease duration (in years) of RA was $6.5 \pm 4.9$. Only one patient had a positive family history for RA. RF positivity was noted in $73 \%$ of the patients. 32 patients were tested for AntiCCPAb, in whom $20(62.5 \%)$ were positive. $26 \%$ of patients had comorbidities (type-2 DM, SHT, Hypothyroidism, CAD, Dyslipidemia).In our study $15 \%$ of patients had cutaneous manifestations like Rheumatoid nodules(4\%), herpes(1\%) and chloroquine induced skin manifestations (10\%) in the form of hypo \& hyperpigmentation, rashes, dry skin and allergic reactions.

\section{RESULTS}

\begin{tabular}{|c|c|c|}
\hline Gender & Female- 97\% & Male- 3\% \\
\hline Age Group & $<40$ Years- $31 \%$ & $>40$ Years $-69 \%$ \\
\hline Disease Duration & $<2$ Years $-28 \%$ & $>2$ Years $-62 \%$ \\
\hline $\mathrm{RF}$ & Positive - $73 \%$ & Negative-27\% \\
\hline Anti CCP Ab & Positive- $62 \%$ & Negative- $38 \%$ \\
\hline Comorbidities & Present- 26\% & Absent-74\% \\
\hline
\end{tabular}

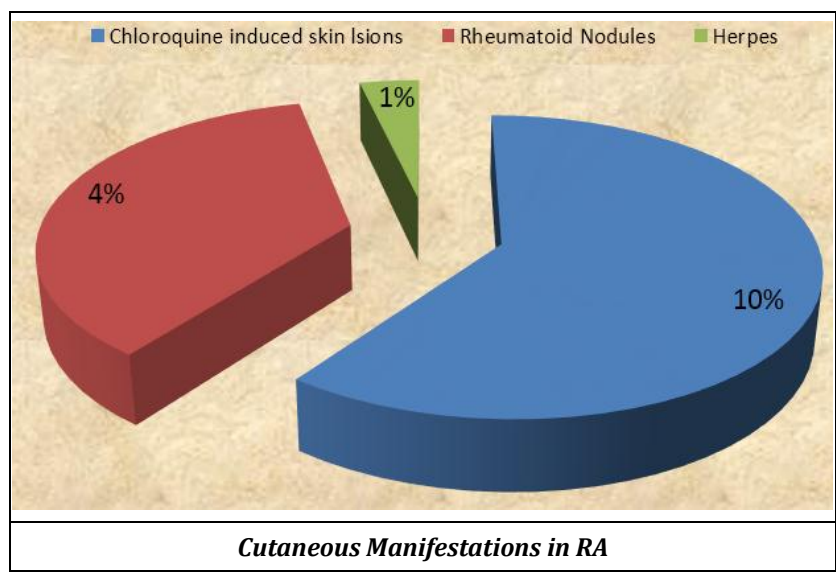

\begin{tabular}{|c|c|c|}
\hline Gender & Female- 93\% & Male- $\mathbf{7 \%}$ \\
\hline Age group & $<40$ Years- $26.6 \%$ & $>40$ Years- $63.4 \%$ \\
\hline Disease duration & $<2$ Years $-44 \%$ & $>2$ Years $-66 \%$ \\
\hline RF & Positive $-80 \%$ & Negative- $20 \%$ \\
\hline Anti-CCP Ab & Positive- $60 \%$ & Negative- $40 \%$ \\
\hline
\end{tabular}

Table 2. Gender, Age Group, Disease Duration, RF, Anti-CCP Positivity Distribution in the RA Patients with Cutaneous Manifestations

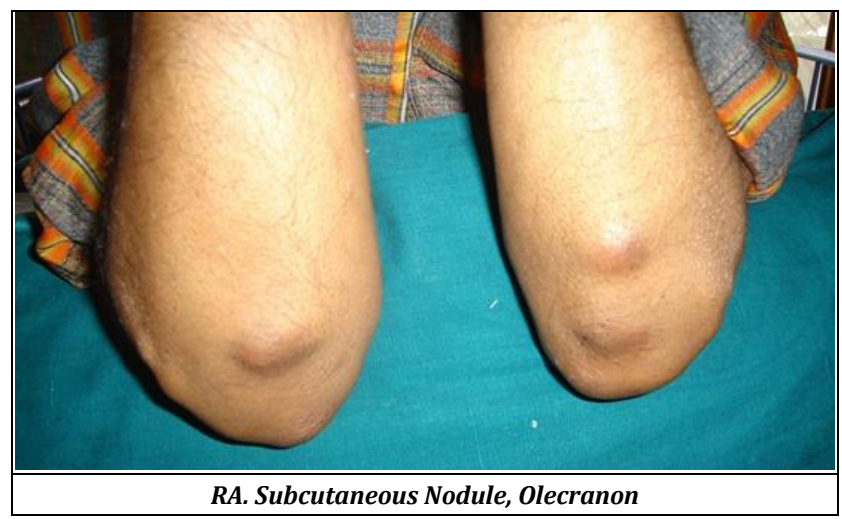

\section{DISCUSSION}

RA is a systemic inflammatory disorder that primarily affects the joints, but frequently exhibit extraarticular, including cutaneous, manifestations. A large burden of cutaneous disease may be a sign of RA disease activity and requires for more aggressive treatment.[8] RA may have a plethora of cutaneous manifestations.[3] The mechanisms of cutaneous affection include activation of inflammatory cells (Neutrophils, lymphocytes, and macrophages), vasculopathy, 
vasculitis, acral deformity, and drugs. ${ }^{[9]}$ Specific skin lesions associated with RA comprise of Rheumatoid Nodules, granulomatous, and neutrophilic dermatitis in the context of immune complex diseases, and rheumatoid vasculitis.[6] While Rheumatoid Nodules are almost exclusively seen in patients with RA, granulomatous and neutrophilic dermatitis may occur in other systemic autoimmune diseases, lymphoproliferative disorders or may be drug-induced. Likewise, rheumatoid vasculitis does not show any apparent clinical or histological difference from other forms of vasculitis.[6],[10] Numerous other nonspecific lesions (including iatrogenic lesions) have also been described in RA patients.

\begin{tabular}{|c|c|c|}
\hline \multicolumn{2}{|c|}{ Due to Disease } & Due to Drugs \\
\hline Specific & Non-Specific & \multirow{9}{*}{$\begin{array}{l}\text { 1. Chloroquine/Hydroxychloroquine: Hyper } \\
\text { \&hypopigmentation of skin \&mucous membranes, } \\
\text { Rash, photosensitivity, alopecia, depigmentation of } \\
\text { hair, dermatitis, bullous pemphigoid }{ }^{8} \text { 2. } \\
\text { Methotrexate: accelerated nodulosis } 3 \text {. } \\
\text { Sulfasalazine: Steven Johnson syndrome, fixed drug } \\
\text { eruption, erythema multiforme, TENS, } \\
\text { photosensitivity 4. Azathioprine: Rashes, herpes } \\
\text { zoster 5. Leflunomide: SJS, TENS, Alopecia 6. Anti- } \\
\text { Cytokines: Psoriasis, vasculitis 7. Steroids, NSAIDS }\end{array}$} \\
\hline Rheumatoid nodu & & \\
\hline Rheumatoid nodulosis & Palmar erythema & \\
\hline $\begin{array}{l}\text { Neutrophilic dermatosis } \\
\text {-sweet syndrome }\end{array}$ & $\begin{array}{c}\text { Atrophic skin } \\
\text { Raynaud }\end{array}$ & \\
\hline -pyoderma gangrenosum & phenomenon & \\
\hline $\begin{array}{c}\text {-PAPA/PAPASH } \\
\text { syndromes }\end{array}$ & Rash & \\
\hline Granulomatous & Asteatotic eczema & \\
\hline dermatitides & Secondary & \\
\hline Rheumatoid vasculitis & amyloidosis & \\
\hline \multicolumn{3}{|c|}{ able 3. Cutaneous Manifestations in RA } \\
\hline
\end{tabular}

\begin{tabular}{|c|c|c|c|c|c|}
\hline 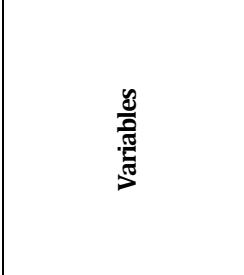 & 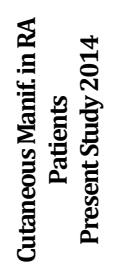 & 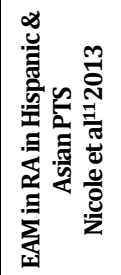 & 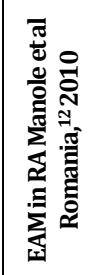 & 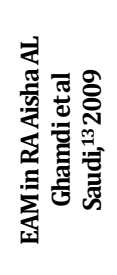 & 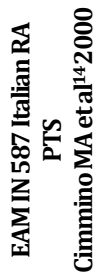 \\
\hline Gender (M/F) & F- $93 \%$ & $\mathrm{M}-\mathrm{m} / \mathrm{c}$ & $\mathrm{M}-\mathrm{m} / \mathrm{c}$ & F- $75 \%$ & $\mathrm{M}-\mathrm{m} / \mathrm{c}$ \\
\hline Disease Duration & Longer $>2 \mathrm{Y}$ & Longer $>8.8 \mathrm{Y}$ & Longer & Longer $>5 \mathrm{Y}$ & NA \\
\hline Co-morbidity & $26 \%$ & NA & NA & $21 \%$ & NA \\
\hline Extraarticular manifestation & NA & $60 \%$ & $40 \%$ & $70 \%$ & $40.9 \%$ \\
\hline Rheumatoid Nodules & $4 \%$ & $17.2 \%$ & $20 \%$ & $3 \%$ & $16.7 \%$ \\
\hline Drug induced Skin Lesions & $10 \%$ & NA & NA & NA & NA \\
\hline OtherSkin Lesions & $1 \%$ & $<1 \%$ & $<1 \%$ & $2 \%$ & NA \\
\hline Skin vs RF Positivity & $80 \%$ & $96 \%$ & +ve Assoc. & $73 \%$ & +veAssoc. \\
\hline Skin vs Anti CCP Positivity & $60 \%$ & NA & NA & NA & NA \\
\hline \multicolumn{6}{|c|}{ Table 4. Comparing Present Study with Other Studies } \\
\hline
\end{tabular}

Patients with RA exhibit geographic and ethnic variations. In a previous study of RA with cutaneous manifestations, there was a male gender preponderance. However, in consonance with the previous Saudi study,[13] there was a female preponderance in the present series. Similar to other studies longer disease duration ( $>2$ years) was seen in the present study.

RNs are the most common specific cutaneous manifestation in patients with RA [15] Classic RNs are movable subcutaneous firm or hard, usually asymptomatic, persistent nodules that usually develop on the extensor surface of the elbow, olecranon, and extensor tendons of the hands, proximal ulna, sacrum, occipital region, and sole.[4] It is noteworthy that all of these areas are prone to friction. They may also occur internally in the spine, lung, heart valve, and gastrointestinal tract]. Rheumatoid factor is almost always present in patients with nodules and RA pts with nodules are more likely to develop vasculitis. The size of nodules varies from $2 \mathrm{~mm}$ to $5 \mathrm{~cm}$, they are firm, nontender and movable in subcutaneous tissue. Cigarette smoking may increase the risk of developing rheumatoid nodules. The precise mechanism of $\mathrm{RN}$ formation is not clear, complement activation following immune complex deposition on vessel walls, fibrin deposition and proinflammatory cytokines have been implicated in the pathogenesis of RN. Histopathologically, palisades of histiocytes surrounding a zone of necrobiosis are usually found.[16]

These nodules are mostly asymptomatic and usually do not require any treatment but occasionally they might ulcerate and become infected. Patients may request treatment in cases of ulceration, infection, nerve compression or limitation of motion. Local glucocorticoid injection could be used to decrease the size and surgical excision is an option in patients who do not respond to the local steroid injection but recurrence at the same site is possible.

The rheumatoid nodules and comorbidity in the present series were $4 \%$ and $26 \%$ respectively similar to study in Saudi. However, studies from Romania, Italy, Asia showed that the rheumatoid nodules occurrence in higher prevalence (16 to $20 \%$ ). A relatively lower occurrence (8.1\%) has also been noted in the present study. In another Indian series, RN was found in $7.5 \%$ patients. ${ }^{[17]} \mathrm{RF}$ positivity was seen among $75 \%$ of the patients with RN. Recently, RN formation has been reported following etanercept and adalimumab. RNs which crop up mostly in the hands and feet in patients without RFs or joint complaints include a condition known as rheumatoid nodulosis or are otherwise known as benign RNs.[9] RA patients receiving MTX treatment may occasionally develop multiple RN (Accelerated nodulosis). The mean period from the beginning of MTX therapy to the onset of subcutaneous nodulosis is about 3 years. No such case has been noted in the present series.

Rheumatoid papules are an additional characteristic cutaneous manifestation associated with RA. Histological features of such papules demonstrate leukocytoclastic vasculitis and palisading granuloma with collagen degeneration, in the more superficial part of the dermis than is the case with RNs. Rarely, rheumatoid papules spontaneously fall of after crusting due to transepidermal elimination. Papular eruptions might also be induced by MTX therapy. Rheumatoid neutrophilic dermatitis clinically manifests as symmetrical erythematous papules, wheal-like erythema, nodules, plaques, and rarely, vesicles, over the extremities, and trunk.

Rheumatoid vasculitis has wide variations of clinical presentations. In the present Chapel Hill Consensus. Conference nomenclature, primary vasculitides in RA is classified under "vasculitis associated with systemic disease."[18] Whereas vessels of any caliber may be involved, the disease more frequently affects small and medium-sized vessels. Clinical manifestations depend on the types of vessels involved and may include palpable purpura, cutaneous ulcers, or haemorrhagic blisters among others. Mononeuritis multiplex is another typical feature of rheumatoid vasculitis. Small digital infarctions may go with other manifestations in clinical vasculitis or may occur alone as isolated digital arteritis.[6],[9]

The incidence of RV has in fact been waning over the last two decades, possibly as a result of the more aggressive management of RA currently used. It remains an important complication of RA that needs to be prompt recognition and treated.[19] The precise aetiology of clinical rheumatoid vasculitis is poorly understood. However, high titers of RF, cryoglobulins, decreased circulating complement, an 
increased prevalence of HLA-DR4, and the pathologic findings support an immune aetiology. Skin biopsy is a useful tool for diagnosis and has a 75\% yield. Histologically all layers of vessel wall are infiltrated by inflammatory cells in addition to fibrinoid necrosis, erythrocyte extravasation and nuclear dust. Isolated nail fold infarcts also known as Bywaters lesions are benign lesions and do not require immunosuppressive treatment due to low risk of progression. He options for treatment of RV are high dose glucocorticoids plus rituximab or high dose glucocorticoids plus cyclophosphamide with azathioprine as maintenance treatment. In a previous Indian series, RV was seen in $5.8 \%$ of patients.[17]In the present study no case of rheumatoid vasculitis reported. On the other hand, chronic leg ulcers with or without oedema are often documented in patients with RA. The aetiology of leg ulcers in RA is multifactorial.

The predominant causes are chronic venous insufficiency, rarely peripheral artery disease, hypertension (Martorell's ulcer), and diabetes mellitus, or a combination of these. It is worth mentioning that vasculitic leg ulcers are relatively rare in the setting of RA.[6] Other causes of leg ulcer include vasculopathy (nonvasculitic vascular disorders of various origins such as, coagulopathy, thrombosis of postcapillary veins, intimal proliferation of small arteries that lead to partial or complete vascular occlusion).[6],[9]

Patients with RA have an increased baseline risk of infections when compared with the general population. ${ }^{[5]} \mathrm{RA}$ patients are often on immunosuppressives which make them further susceptible to develop secondary viral, bacterial, or fungal infections. ${ }^{[20]}$ Ziemer et al. observed such infections in $7.5 \%$ of their patients. ${ }^{[6]}$ In our study herpes infection seen in $1 \%$.

In addition to manifestations related to the disease, there are also diverse dermatologic features related to the medications used to treat RA.[16]. Chloroquine/ hydroxychloroquine can cause hyper \&hypopigmentation of skin \& mucous membranes, Rash, photosensitivity, alopecia, depigmentation of hair, dermatitis, bullous pemphigoid. Steven Johnson syndrome, fixed drug eruption, erythema multiforme, TENS, photosensivity has been reported with Sulfasalazine. Leflunomide can cause alopecia and a maculopapular skin rash in $10 \%$ to $12 \%$ of patients.

Anti-TNF $\alpha$ agents, in particular, have a wide variety of adverse effects including psoriasiform eruptions, granulomatous conditions, and cutaneous connective tissue disorders, great vessels arteritis. ${ }^{[8]}$ Justice et al. reported a case of widespread cutaneous herpes simplex virus type 1 infection following treatment with infliximab.[21] Pustular psoriasis [20] and MTX-related lymphoproliferative disorder with extensive vascular involvement have also been described recently.[22] Raynaud's phenomenon (RP) is an exaggerated response to cold temperature or stress. An episode of RP is characterized by onset of cold fingers followed by sharply demarcated skin colour changes (white, blue and red). Primary RP usually includes patients with no underlying cause and secondary RP when associated with various autoimmune diseases including RA. The exact mechanism of Raynaud's phenomenon in patients with RA is unclear but the proposed mechanisms are a procoagulant tendency, endothelial injury and reduced vasodilatation. Treatment options include calcium channel blocker, phosphodiesterase (PDE) inhibitor and topical nitroglycerin.
In patients resistant to initial therapy, recurrent digital ulcers, threatened digital loss, IV infusions of prostaglandins (e.g. iloprost), endothelin-1 inhibitors (e.g. bosentan) or chemical/surgical sympathectomy has been used. In a previous series of patients with RA and skin lesions, 73\% to $93 \%$ of the patients were RF positive.[4] A comparable percentage $(80 \%)$ of patients of the present series had positive RF. in our study $60 \%$ of RA patients with skin lesions were anti-CCP positivity. However, there was no statistically significant difference of occurrence of Rheumatoid Nodules and drug (chloroquine) induced skin lesions between the RF positive and negative groups in the current series.

\section{Limitations}

Being an institution-based study, the study results may not reflect the true situation in the community. Furthermore, there was no control group in the present descriptive case series.

\section{CONCLUSIONS}

The present study highlighted the patterns of mucocutaneous manifestations in an Indian population. Some features showed discordance to western data which might be attributed to ethnic variations. Thus, understanding the aetiology and management for cutaneous manifestations of RA will optimize patient care. We would further like to emphasize that every physician caring for patients with RA should be aware of these relatively common dermatologic complications.

\section{REFERENCES}

[1] Marzano AV. Cutaneous manifestations in rheumatoid arthritis. Clin Dermatol 2013;2:53-9.

[2] Sharma A, Albert D. Dermatologic manifestations of rheumatoid arthritis. Rheumatology (Sunnyvale) 2015;5(3):168.

[3] Sayah A, English JC 3rd. Rheumatoid arthritis: a review of the cutaneous manifestations. J Am Acad Dermatol 2005;53(2):191-209.

[4] Ergun T, Inanc N, Tuney D, et al. Skin manifestations of rheumatoid arthritis: a study of 215 Turkish patients. Int J Dermatol 2008;47(9):894-902.

[5] Hata T, Kavanaugh A. Rheumatoid arthritis in dermatology. Clin Dermatol 2006;24(5):430-7.

[6] Ziemer $M$, Müller AK, Hein $G$, et al. Incidence and classification of cutaneous manifestations in rheumatoid arthritis. J Dtsch Dermatol Ges 2016;14(12):1237-46.

[7] Arnett FC, Edworthy SM, Bloch DA, et al. The American Rheumatism Association 1987 revised criteria for the classification of rheumatoid arthritis. Arthritis Rheum 1988;31(3):315-24.

[8] Xue Y, Cohen JM, Wright NA, et al. Skin signs of rheumatoid arthritis and its therapy-induced cutaneous side effects. Am J Clin Dermatol 2016;17(2):147-62.

[9] Yamamoto T. Cutaneous manifestations associated with rheumatoid arthritis. Rheumatol Int 2009;29(9):979-88. 
[10] Scott DG, Bacon PA. Intravenous cyclophosphamide plus methylprednisolone in treatment of systemic rheumatoid vasculitis. Am J Med 1984;76(3):377-84.

[11] Richmann NC, Yazdany J, Graf J, et al. Extra articular manifestations of rheumatoid arthritis in a multiethnic cohort of predominately Hispanic \& Asian patients. Medicine (Baltimore) 2013;92(2):92-7.

[12] Cojocaru M, Cojocaru IM, Silosi I, et al. Extra-articular manifestations of rheumatoid arthritis. Maedica (Buchar) 2010:5(4):286-91.

[13] Al-Ghamdi A, Attar SM. Extra articular manifestations of rheumatoid arthritis: hospital-based study. Ann Saudi Med 2009;29(3):189-93.

[14] Cimmino MA, Salvarani C, Macchioni P, et al. Extra articular manifestations in 587 Italian patients with rheumatoid arthritis. Rheumatol Int 2000;19(6):213-7.

[15] Douglas KM, Ladoyanni E, Treharne GJ, et al. Cutaneous abnormalities in rheumatoid arthritis compared with non-inflammatory rheumatic conditions. Ann Rheum Dis 2006;65(10):1341-5.

[16] Weedon D, Strutton G, Rubin AI. Weedon's Skin Pathology. $3^{\text {rd }}$ edn. Philadelphia: Elsevier 2010.
[17] Prakash B, Jayashankar CA, Shivalingappa VM, et al. Cutaneous manifestations of rheumatoid arthritis. IJRCI $2015 ; 3(1)$

[18] Jennette JC, Falk RJ, Bacon PA, et al. 2012 revised International Chapel Hill Consensus Conference Nomenclature of Vasculitides. Arthritis Rheum 2013;65(1):1-11.

[19] Genta MS, Genta RM, Gabay C. Systemic rheumatoid vasculitis: a review. Semin Arthritis Rheum 2006;36(2):88-98.

[20] Justice EA, Khan SY, Logan S, et al. Disseminated cutaneous herpes simplex virus-1 in a woman with rheumatoid arthritis receiving infliximab: a case report. J Med Case Rep 2008;2:282.

[21] Cestelli V, Spinella A, Campomori F, et al. Large vessel vasculitis occurring in rheumatoid arthritis patient under Anti-TNF Therapy. Case Rep Med 2014;2014:624184.

[22] Shimura C, Satoh T, Takayama K, et al. Methotrexaterelated lymphoproliferative disorder with extensive vascular involvement in a patient with rheumatoid arthritis. J Am Acad Dermatol 2009;61(1):126-9. 